\title{
MNESARETE MARIANA NOVA ESPÉCIE DE LIBÉLULA DA CHAPADA DIAMANTINA, BAHIA, BRASIL (ODONATA, CALOPTERYGIDAE)
}

\author{
Angelo B.M. Machado ${ }^{1}$
}

\begin{abstract}
MNESARETE MARIANA NEW SPECIES OF DRAGONFLy FROM CHAPADA DiAMANTINA, Bahia, Brazil (Odonata, CAlopterygidaE). Mnesarete mariana sp.n. is described based on three male specimens collected at Chapada Diamantina, in the Bahia State, Brazil. The new species is close to $M$. guttifera (Selys, 1873) but differs from it mainly by structure of the inferior anal appendages and by the presence of a tuft of hairs on each side of the hind part of the anterior lamina adjacent to the anterior hamuli. The appendages of $M$. guttifera are now illustrated for the first time.

KEY WORDS. Odonata, Calopterygidae, new species, Chapada Diamantina
\end{abstract}

A família Caloptrygidae está representada na região neotropical por apenas três gêneros: Hetaerina Hagen, 1853, Iridyction Needham \& Fisher, 1940 e Mnesarete Cowley, 1934. Iridyction tem distribuição restrita às regiões montanhosas da Venezuela e Guiana Inglesa, Hetaerina estende-se também à região neártica, enquanto Mnesarete distribui-se exclusivamente na América do Sul. Com 20 espécies conhecidas (GARRISON 1991; BRIDGES 1994), das quais 12 ocorrem no Brasil (TsUDA 1986), este gênero é muito semelhante a Haeterina, tanto do ponto de vista morfológico (GARRISON 1990), como ecológico, uma vez que ambos contêm apenas espécies de ambientes lóticos.

Durante recente viagem de coleta à Chapada Diamantina, no centro da Bahia, tivemos oportunidade de encontrar uma nova espécies de Mnesarete, que é agora descrita e ilustrada. A nova espécie é muito semelhante à M. guttifera (Selys, 1873), espécie ainda pouco conhecida, cujos apêndices anais são ilustrados pela primeira vez.

\section{Mnesarete mariana sp.n.}

Figs $1-2$

Descrição do macho. Coloração e nervação: lábio preto. Labro amarelo com uma mancha mediana negra afilando-se anteriormente. Base das mandíbulas e genas amarelas. Anteclípeo negro com uma mancha central amarela. Pós-clípeo verde metálico. Parte superior da cabeça negra com pruinosidade branca na porção anterior da fronte. Antenas negras com o escapo amarelado. Tubérculos occipitais ausentes. Protórax negro com reflexos esverdeados fracos e pruinosidade branca

1) Departamento de Zoologia, Instituto de Ciências Biológicas, Universidade Federal de Minas Gerais, Caixa Postal 486, 31270-901 Belo Horizonte, Minas Gerais, Brasil. 
lateral. Pterotórax escuro com reflexos metálicos esverdeados e estreita faixa amarelada ao longo da segunda sutura lateral e da parte posterior do metaepímero. Pruinosidade branca presente ao longo da segunda sutura lateral e na parte ventral do pterotórax. Em um dos parátipos, imaturo e ainda desprovido de pruinosidade, todo o pterotórax apresenta coloração verde metálica com reflexos cúpreos no metaepímero e linha amarelada ao longo da metade inferior da sutura humeral. Pernas negras com pruinosidade branca nas coxas, nos dois exemplares maduros. Asas hialinas com mancha apical marrom, maior nas asas posteriores e ausente nas anteriores do parátipo imaturo. Antenoidais nas asas anterior e posterior 20. Pósnodais nas asas anterior e posterior 27-28. Duas séries de células, em uma extensão de 10 células entre $\mathrm{Al}$ e a margem, na asas posterior, Pterostigma ausente. Abdômen, inclusive os apêndices anais, negro com pruinosidade branca no primeiro segmento e na metade anterior do segundo, exceto no exemplar imaturo.

Caracteres estruturais. Décimo segmento abdominal com carena dorsal mediana baixa, não prolongada em espinho. Apêndices anais superiores como nas figuras 1-2. Apêndices anais inferiores (Figs 1-2) em vista dorsal encurvados medialmente (Fig. 1); em vista lateral encurvados dorsalmente no terço distal estendendo-se até um pouco menos da metade $(0,40)$ do comprimento dos apêndices anais superiores (Fig. 2). Ápice dos apêndices anais inferiores (Figs 1-2) truncado e provido de três pequenos tubérculos, sendo o distal mais proeminente. Lâmina anterior lisa, com tufos de pêlos amarelados de cada lado de sua parte posterior, adjacentes aos hâmulos anteriores. Fenda da lâmina anterior ocupando o terço anterior do segundo segmento. Hâmulo posterior com pêlos em sua parte anterior.

Medidas (mm). Asa anterior: comprimento 30, largura máxima 6,4. Asa posterior: comprimento 29,5, largura máxima 6.4. Abdômen com apêndice: 40 . Apêndices anais superiores $1,4-1,5$, inferiores $0,5-0,7$. O parátipo imaturo é um pouco menor que os demais exemplares (asa anterior 27,0, asa posterior $26,5 \mathrm{e}$ abdômen 35,0$)$.

Fêmeas desconhecida.

Material examinado. BRASIL, Bahia: Chapada Diamantina, holótipo e um parátipo, Rio de Contas, 1300m, 21-IV-1995; um parátipo, Capão, Palmeiras, 1200 m, Angelo B.M. Machado, Paulo A.R. Machado \& Eduardo R. Machado leg. Holótipo e um parátipo depositados na coleçãodo autor, em Belo Horizonte. Um parátipo depositado na coleção do Departamento de Zoologia, Instituto de Ciências Biológicas, Universidade Federal de Minas Gerais, Belo horizonte.

O material de Rio de Contas foi coletado em um pequeno córrego que cruza a estrada que liga esta cidade ao Pico das Almas, em área de campo rupestre. $\mathrm{O}$ exemplar de Capão foi coletado em um córrego com mata ciliar que desce da montanha na vizanhança do Parque Nacional Chapada Diamantina, sendo provável que a espécie também ocorra nesse Parque.

Discussão. Pela ausência de pterostigma, asas estreitas e hialinas, $M$. mariana enquadra-se no grupo aenea de SELYS (1880), sendo bastante próxima de $M$. guttifera. Essa espécie foi descrita originalmente de São João del Rei, Minas Gerais (SELYS 1873) e assinalada também em Chapada dos Guimarães, Mato Grosso (CALVERT 1909; LONGFIELD 1929). Seus apêndices anais não haviam ainda sido 

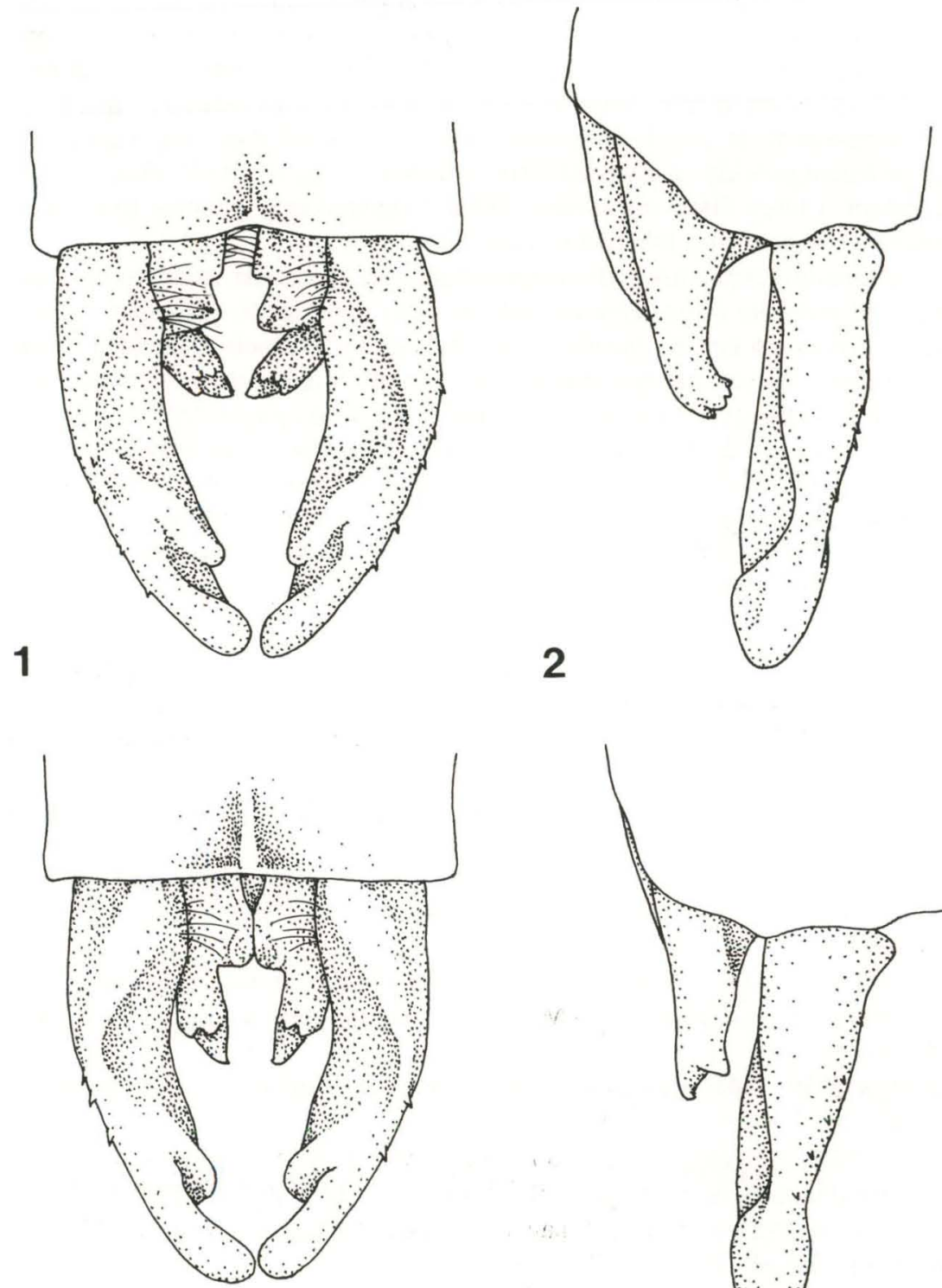

3

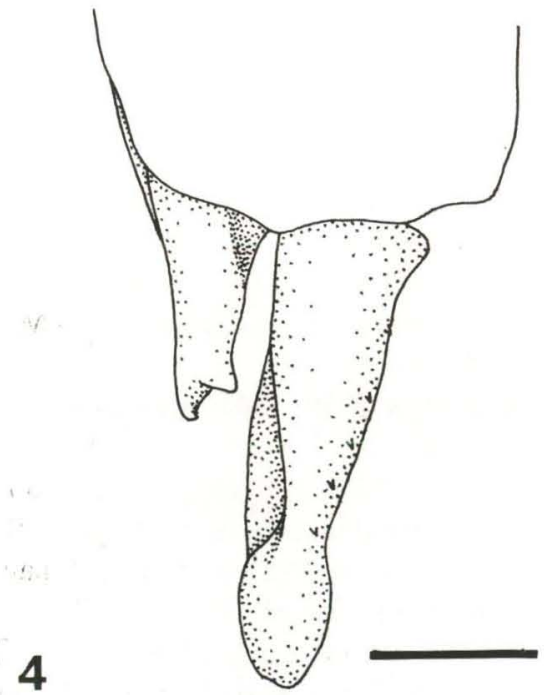

Figs 1-4. (1-2) Mnesarete mariana sp.n. holótipo macho, apêndices anais em vista dorsal (1) e lateral (2). (3-4) Mnesarete guttifera (Selys, 1873), São Tomé das Letras, Minas Gerais, próximo da localidade-tipo São João del Rei, apêndices anais em vista dorsal (3) e lateral (4). Barra $=0,05 \mathrm{~mm}$. 
ilustrados, o que dificultava sua correta identificação. As figuras 3-4 mostram esses apêndices, desenhados com base em um exemplar por nós identificado por comparação com os síntipos de São João del Rei, depositados na coleção Selys-Longchamps, em Bruxelas. Verifica-se que os apêndices anais superiores de $M$. guttifera (Figs 3-4) são praticamente idênticos aos de $M$. mariana (Figs 1-2). Já os apêndices anais inferiores de M. guttifera são retos, possuem o ápice bífido (Fig. 4), sendo o ramo proximal provido de dois pequenos tubérculos (Fig. 3). Em M. mariana eles apresentam o terço distal encurvado dorsal e medialmente, o ápice truncado e provido de três pequenos tubérculos (Figs 1-2).

Outra diferença entre as duas espécies pode ser observada na lâmina anterior, que em M. mariana é lisa, com um tufo de pêlos amarelados adjacente ao lobo posterior, enquanto em $M$. guttifera é revestida de pubescência amarelada sem o tufo de pêlos. Outro caráter que separa M. mariana de M. guttifera é a presença, nos exemplares maduros, de uma pequena mancha apical nas asas anteriores. Nos 25 exemplares machos de $M$. guttifera examinados, essa mancha ocorreu em apenas dois exemplares (8\%). Entretanto, a real importância desse caráter só poderá ser estabelecida com segurança, após estudo de material mais abundante de M. mariana.

Dedico esta libélula à minha neta Mariana, nascida quando este trabalho estava sendo elaborado.

AGRADECIMENTOS. A Paulo A.R. Machado e Eduardo R. Machado, que me acompanharam na viagem à Chapada Diamantina, para coleta de material odonatológico e, assim, participaram da descoberta de M. mariana. A Myriam M. Duarte, pelos desenhos que ilustram este trabalho.

\section{REFERÊNCIAS BIBLIOGRÁFICAS}

BRIDGES, C.A. 1994. Catalogue of the family-group, genus-proup and speciesgroup names of the Odonata of the world. Urbana, author's edition, $3^{\text {rd }}$ ed., 972p.

CALVERT, P.P. 1909. Contributions to a knowledge of the Odonata of the neotropical region, exclusive of Mexico and Central America. Ann. Carn. Mus. 6: $73-280$.

Garrison, R.W. 1991. A synonymic list of the New World Odonata. Argia 3 (2): 1-30.

1990. A synopses of the genus Hetaerina with descriptions of four new species (Odonata: Calopterygidae). Trans. Am. Ent. Soc. 116 (1): 175-259.

LONGFIELD, C. 1929. A list of Odonata of the state of Mato Grosso, Brazil. Trans. Ent. Soc. Lond. (1): 125-139.

Selys-LongChampS, M.E. 1873. Troisièmes additions au synopsis des Caloptérygines. Bull. Acad. R. Belg. 35 (5): 469-519. 1880. Laïs devillei. C.R. Soc. Ent. Belg. 23: 44-51.

TsuDA, S. 1986. A distributional list of World Odonata. Osaka, author's edition, $246 \mathrm{p}$.

Recebido em 16.VIII.1996; aceito em 07.XI.1996 